\title{
Interdisciplinary diagnostics in the process of revitalization of historic buildings, in terms of changing their function
}

\author{
Wojciech Terlikowski ${ }^{1, *}$ \\ ${ }^{1}$ Warsaw University of Technology, The Institute of Building Engineering, al. Armii Ludowej 16, 00- \\ 637 Warsaw, Poland
}

\begin{abstract}
Revitalization of historic buildings in crisis areas is a complex, interdisciplinary process that addresses not only the technical problems of buildings, but also the social, environmental, economic and cultural issues of the local community. Proper diagnosis of the dangers and social problems in the crisis area should be the basis for identifying new functionalities for this area. It should help to resolve the diagnosed problems, as well as to stimulate growth and revival in all spheres related to the life of the local community. The construction process, which results in the change of the function of the building and its adaptation to modern demands - technical, utility and formal, requires innovative interdisciplinary diagnostic methods. Each building, its structure and its components, has a certain adaptability that can be presented in a measurable and comparable manner. Evaluation of adaptability is a part of the expanded, interdisciplinary diagnostics of the historic building, which should be applied in the process of its revitalization. Determination of adaptability is an element of wider diagnostic procedures, which results in assessment of the revitalization capacity of a building.
\end{abstract}

\section{Change of functions of historic buildings in the process of revitalization}

Revitalization is an interdisciplinary process which main purpose is to revitalize a specific area that, in accordance with objective evaluation and diagnostic tests, is in a state of crisis [1]. Crisis is a set of undesirable, destructive processes that take place in the spatial, social and economic spheres, causing permanent degradation of the area of occurrence. The complexity of the revitalization process consists in simultaneously conducting spatial, building-architectural, urban, social and economic changes. They are usually undertaken in the public interest and include, among others, restoration of the revitalized area to its former functions, or to create new ones and to create conditions for its further development.

* Corresponding author: w.terlikowski@ili.pw.edu.pl 
The change of function is particularly important for historic buildings in a crisis area [2]. Historical buildings are usually central objects of these areas and the process of degradation starts from them. Degradation of buildings - in the material, functional and social spheres, directly affects the degradation of the area. The poor technical condition of the structures of historic buildings is often a result of the age of the buildings, their improper use and the wear of structural elements that constitute the building's supporting structure. This usually jeopardize the safety of construction and use. An abandoned and unused building usually falls into a state of ruin because of the acceleration of destructive activities. Lack of management of the building and its surroundings results in pathological behavior, which increases the social risk by deepening the crisis.

Correct diagnosis of the dangers and social problems in the crisis area should be the basis for identifying the new functionalities for this area. They should help to resolve the diagnosed problems, as well as to stimulate the development and revival in all spheres related to the life of the local community. It is clear that the key issue is the proper selection of utility functions of buildings located in the revitalized area. In the process of revitalization of a historic building as an adaptation to the needs of a given area by the application of specific technical solution, the effect could be obtained in beyond-technical issues - social, economic, cultural, educational and environmental. It derives from the definition of revitalization as well as the principles of sustainable development [3] in the civil engineering.

\section{Technical and formal conditions of changes in the function of historic buildings}

Changing the function of a historic building is often a difficult task and requires the conservator's permission. For formal reasons, changing the function of historic buildings is often not possible. According to the Act on the Protection of Monuments and the Care of Monuments [4] (Article 3, point 1), a monument is a property or a movable property, parts or assemblies that are made by human or related to its activity and constitute a testimony of a past age or event, whose protection is in the public interest because of their historical, artistic or scientific value. According to the Act [4] (Article 7) there are four forms of protection of monuments in Poland:

- entry in the register of monuments,

- recognition as a monument of history,

- creating a cultural park,

- define protection in a local land use plan or in a decision to establish a public purpose location, a decision to authorize a road investment, a decision to set a railway line, or a decision to authorize an airport investment project.

Historical buildings [4] (Article 9 point 1) are included in the "register of monuments". The basis of the entry is the decision of the voivodeship conservator of monuments, issued ex officio, at the request of the owner of immovable monument or perpetual lessee of land on which a permanent monument is located. According to the Act, other elements such as the surroundings of a registered monument and the geographical, historical or traditional names of this monument may be entered in the register. As it appears from the above records, the utility function of buildings included in the register of monuments may also be protected. This means that it may not be possible to change this feature.

Changing the function of a historic building may often involve the need to change the architectural and structural layout, which may even imply a change in the entire footing of a building or its part. The preservation of the architectural form of the monument and its building elements is directly related to the rules governing its protection. It applies to: the dimensions of the roof, the type of roof structure and the type of roofing, the facade 
design and composition, architectural details and construction joinery, the type of building materials used, the traditional architectural and functional arrangement of the building. All these requirements, and often - restrictions, are placed in the local spatial development plan of each municipality. They are justified because a change of the architectural and structural system obviously reduces the historic value of the monument. The preservation of the original architectural and functional layout is particularly important when it concerns historic buildings representing specific, often unique representatives of architectural styles that characterize historical epochs. In the local spatial development plan, arrangements for the protection of monuments of architecture and construction should be made, including : - defining the protected values of existing buildings (historical line of construction, form and size of buildings, form of roofs, facade design, colors, materials, etc.) and establishing a ban on its alteration or restoration order, - rules of land development - building plots (location of buildings);

- definition of acceptable changes and conditions of their implementation;

- definition of dimensions and aesthetic, technical and utility parameters for the new building (course of the building line, form and size of the objects, form of the roofs, development of the facade, colors, materials, etc.);

- maintenance, restoration or redistribution of the parcel division (basic element of organization and space physiognomy);

- identification of other elements of the landscape context (including greenery, pavement and accompanying small architectural objects) to maintain or restore protected values.

Among the historic buildings subjected to revitalization processes three types of buildings can be distinguished:

- buildings used with a function unaltered from the moment of implementation (designed function = implemented function),

- buildings used with the function changed during the use of the building (designed function $\neq$ implemented function), with the adaptation of the building to the new function,

- buildings used with the function changed during the use of the building (designed function $\neq$ implemented function), without the adaptation of the building to the new function

The use of a building with a function incompatible with the originally designed function negatively affects its technical condition. This can even contribute to the deterioration of the structural safety and usability, as well as to the reduced durability of the structure, the finishing materials and the décor of the building. Adaptation to new functions often results in changes to the original architectural-architectural system that can radically change the original layout and be irreversible. In such a case analysis of these changes are necessary in order to properly determine the functional capabilities of a revitalized historic building.

Changing function of a historic buildings implies the necessity of assessing the basic requirements of buildings, and in particular [2] the safety of construction and safety of use. Adaptation of a historic building to a new function usually involves the adaptation of the architectural-structural system, installations and equipment of the building. All this, and especially the interference with the existing structure of the historic building, often destroyed or worn, in addition to the usual revitalization activities, may cause additional effects resulting from adaptation:

- force the change of the structural system or its part,

- force the usage of additional stiffening elements and structural solutions resulting from the weakening of the stiffness of the building,

- stiffening or replacing of basic structural elements such as walls, ceilings, columns, resulting from their weaknesses, by making new communication holes and new architectural arrangements in them, as well as by increasing or changing of loads,

- adaptation, strengthening, repair, replacement of ceilings and other structural elements (Fig.1); 


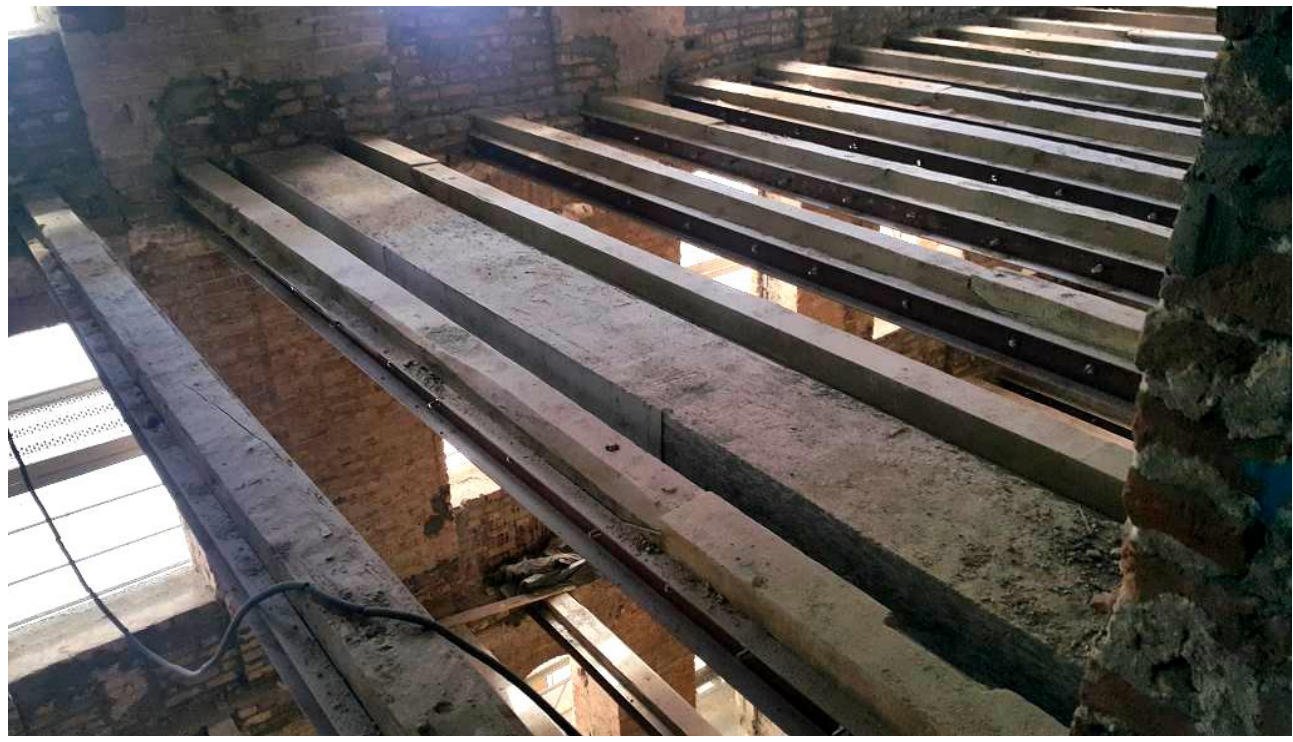

Fig. 1 Ceilings stiffened with steel beams with reinforced concrete strips in the thickness of the floor in the building at ul. Hoża 42 in Warsaw (photo by W. Terlikowski)

- change of existing architectural layout, adaptation of courtyards (Fig.2), extension, superstructure;

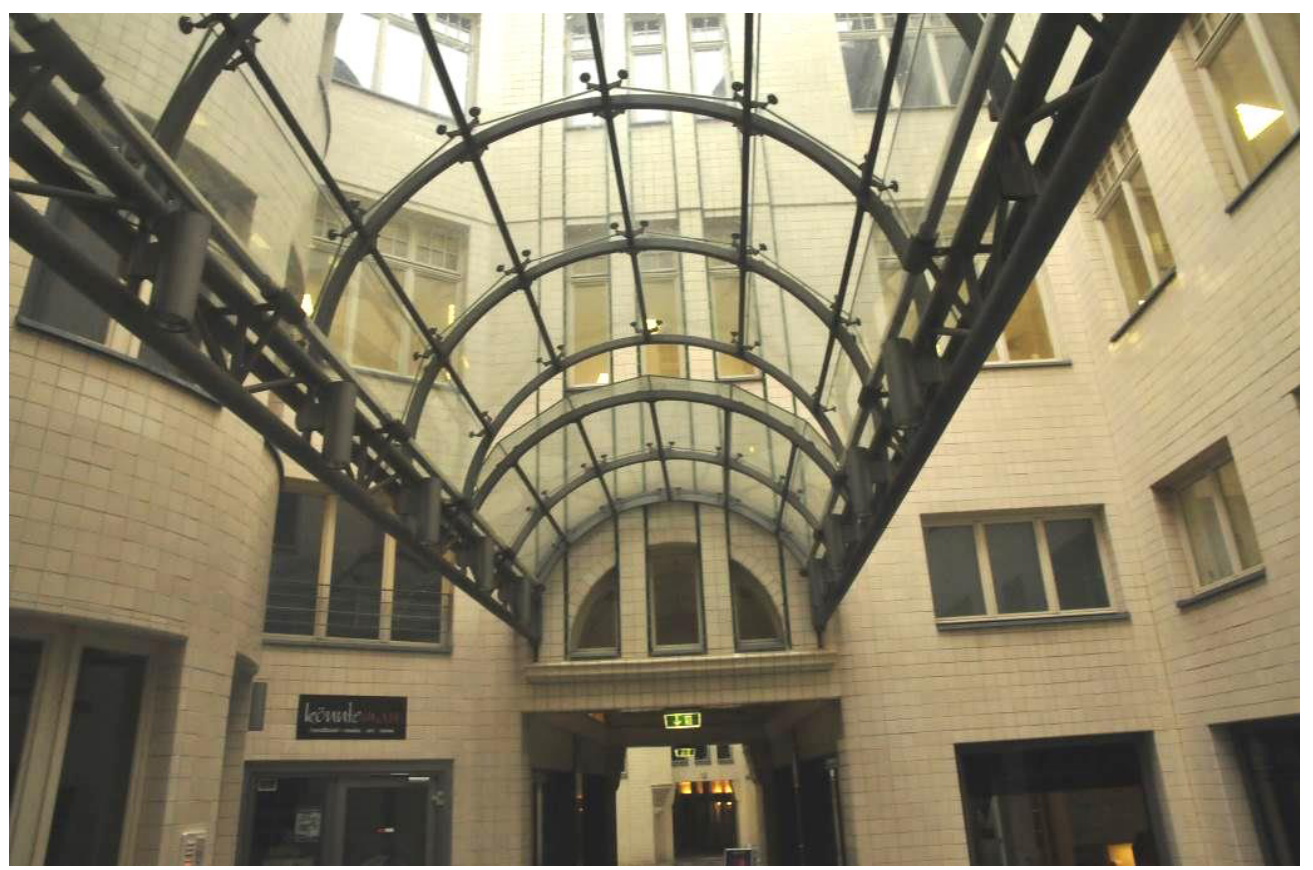

Fig. 2. The roofing of historic building in the old town of Leipzig (Photo: W. Terlikowski)

- force the adaptation, stiffening, repair, replacement of ceilings and other structural elements, 
- force the implementation of new installations, including such disturbing the existing structure,

- installation of new equipment and fittings and new finishing elements,

- force the repair, expansion, raise, strengthen of foundations, due to the increment of stresses under them.

In many historic buildings, the usability of premises and buildings has been changed during their use, for example the original residential function (in palaces, mansions, residences, villas) has been transformed into a public function (offices, hotels, commercial functions). This trend is current in modern times. All structural changes in historic buildings leave a trace in the form of genetic transformations. Under the concept of genetic transformation of the structure of historic buildings, it is necessary to understand all the changes that took place in the history of the object, in relation to the initial pattern of construction technology and materials (for example changing brick bonding in the structure of the wall, the type of mortar or masonry units) [5]. According to [5] the following types of structural systems can be distinguished:

- not transformed structural systems, characterized by original, period-specific construction technology, construction materials that were used, architectural and structural design, composition, with the primary function of the whole object and individual rooms preserved; - construction systems transformed in terms of structure, technology, form, function in the past that partially or to a large extent meet the requirements and characteristics of a given historical age, although they are actually reconstructed by anastylosis or materials and elements analogous to primary ones in primary technology or reproducing primary technology;

- structural systems transformed in such a way that the structure, technology, form, function, decor lost the features of historical authenticity, differing substantially from the original.

In all types of structural systems, remembering the principles of preservation and rehabilitation of historic buildings, it is necessary to properly assess their historical and scientific value using the criteria of authenticity, age, aesthetic, decorative, emotional and social values. The reliable assessment of these values is necessary when a proper assessment regarding the possibility of changing the function is made that results in an interference with the architectural and structural system. Sometimes the restoration of the primary function may involve the removal of transformations made during the period of early use of the building.

\section{Adaptability of building and structural elements}

Adaptability of a building [6] and its components is a set of features and properties that determine its adaptation to new functional and structural conditions (work in old or new structural systems, implying specific static schemes, the possibility of changes, repairs, exchanges, changes of loads resulting from new imposed loads, etc.). Specific load-bearing systems, in defined architectural systems, imply specific functional solutions. This relationship is reversible - the specific usable function determines the appropriate architectural-structural solution. The different structural systems of buildings have different adaptive capabilities, which in consequence allows for functional changes in various ways. Different types of wall systems (longitudinal, transverse, cross and mixed) provide high spatial rigidity of the building, but give no freedom in shaping the interior space of the building. They are designed for functions where multiple rooms can be used, divided by walls- residential, offices. Skeletal systems give the possibility of arbitrary shaping of space, without interference with the architectural and structural system. However, these are 
structures that have less spatial stiffness and are therefore more susceptible to all structural changes.

In order to objectify and regulate the assessment of the adaptability of a building and its components, specific points may be assigned to certain features. That provide the ability to perform a SMART analysis that can show the strengths and weaknesses of an adaptive project and identify potential advantages and problems to solve. Table 1 summarizes the characteristics of the selected types of ceilings found in historic buildings in Poland. Table 1 uses the symbols: 0,1,2,3,4 - rating scale, w- most often necessary replacement, + applied, - not applied, +/- sometimes used certain types.

Table 1. Evaluation of selected properties of the historical ceiling to determine the adaptability [6].

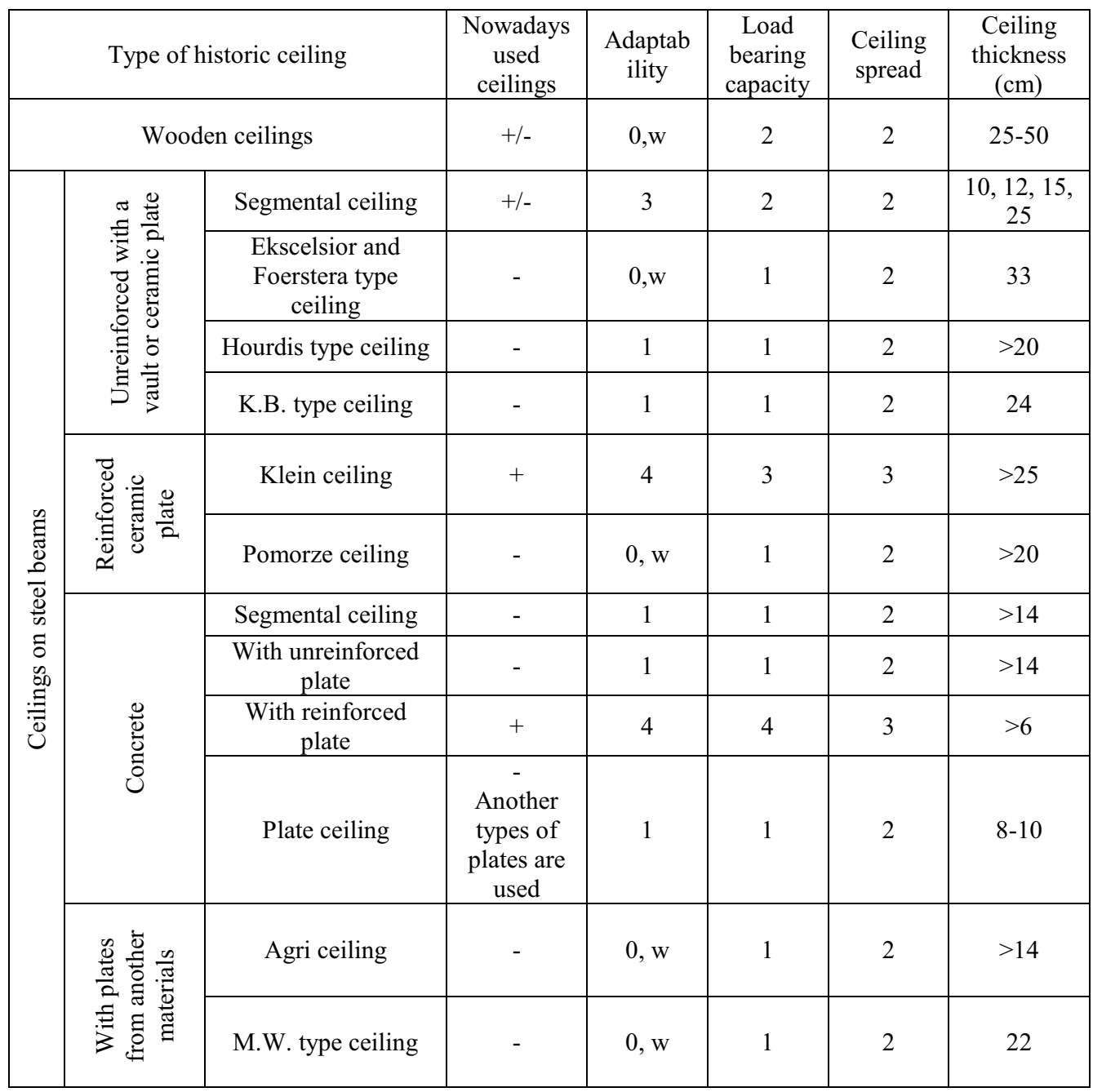

By analogy, all structural elements of the building's supporting system must be analyzed. Only such an extended analysis can provide a full representation of the adaptability of an existing structure. While assessing the adaptability of a historic building, some various aspects of this issue should be taken into account, including the adaptability of the entire building's load bearing system, the adaptability of structural components, the foundation, walls, columns, ceilings, beams, etc., possibility of adaptation to new functions 
(possibility of changing the load values, static schemes, architectural and constructional systems), possibility of adaptation of the building to the needs of the disabled people, possibility of improving the energy efficiency of the building partitions and the whole building.

\section{Interdisciplinary diagnostics - assessment of the revitalization capacity of historic buildings}

The assessment of the adaptability of a historic building, beyond the area of standard technical diagnostics, is part of extended, interdisciplinary diagnostics (Figure 3).

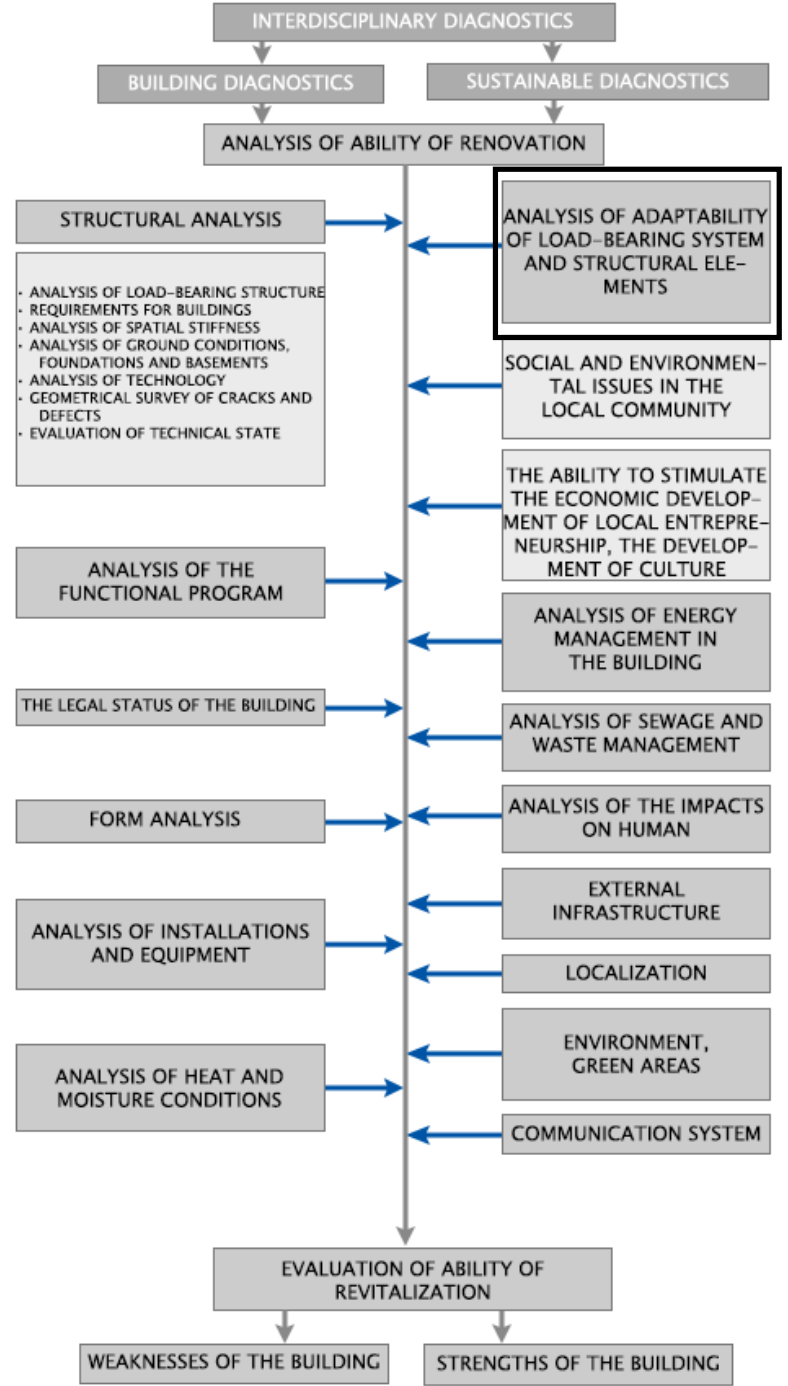

Fig. 3. Diagram of interdisciplinary diagnostics with adaptability analysis [7].

Such diagnostics should be used in the process of revitalization of historic buildings. It consists of examination of all technical and non-technical aspects of the state of the revitalized building, taking into account those resulting from the definition of revitalization and the principles of sustainable development. Such a diagnosis is the assessment of the 
revitalization capacity of a historic building, in which the assessment of adaptability is an element. The revitalization capacity [7] of a building (including the historic one) is a set of features, properties and states of the building, its construction, form, function, location, environmental, social and health values, and the economic viability of the planned revitalization including all aspects of revitalization and the principle of sustainable development [3].

\section{Conclusion}

Changing the function of a historic building is often a crucial part of the process of revitalization of the area where the building is located. It is an important tool for revitalization, through which not only technical and functional changes to the building are made, but above all, the problems of the local community are being solved. The construction process, which results in the change of the function of the building and its adaptation to modern demands - technical, utility and formal - requires innovative interdisciplinary diagnostic methods. Each building, its structure and its components have a certain adaptability that can be measured in a measurable and comparable manner. Evaluation of adaptability is part of the expanded, interdisciplinary diagnostics of the historic building, which should be applied in the process of its revitalization. Evaluation of adaptability is an element of wider diagnostic procedures, which results in assessment of the revitalization capacity of a building

\section{References}

1. N. Doratli, S. Hoskara, M. Fasli, Cities 21, 329 (2004)

2. D. Dvornik Perhavec, N. Šuman., J. Civ. Eng. Arch. 7, 712 (2013)

3. L. Czarnecki, M. Kaproń, Int. J. Soc. Mat. Eng. Res. 17, 99 (2010)

4. Act on the Protection of Monuments and the Care of Monuments (Dz. U. 80., Warsaw, 2003)

5. W. Borusewic, Konserwacja zabytków budownictwa murowanego (Arkady, Warsaw, 1985)

6. W. Terlikowski, Mat. Bud. 9, 82 (2013)

7. W. Terlikowski, JCEEA 33, 531 (2016) 